\title{
Alkylation of Indenyllithium and Alkylindenyllithium Compounds
}

\author{
LENNART MEURLING
}

Department of Organic Chemistry, University of Uppsala, Box 531, S-751 21 Uppsala, Sweden

The reactions between indenyllithium and various halides (methyl, ethyl, isopropyl, $t$-butyl, benzyl, benzhydryl, and triphenylmethyl) gave almost exclusively the corresponding 1-alkylindene ( $\mathrm{Ia}$ ) in good yields. Methylindenyllithium gave a mixture of 1-alkyl-3. methylindene (IIb) and 1-alkyl-1-methylindene (IIc) when treated with alkyl halide in ether. Methylation of alkylindenyllithium compounds methyl-, ethyl-, $t$-butyl- and benzyl-) with methyl iodide gave the corresponding 1 . methyl-3-alkylindenes (IIa) in good yields and only slightly contaminated with 1-alkyl-1methylindene (IIc). The reactions offer a convenient synthetic route from indene to 1,3 dialkylindenes and especially to the least stable tautomer (IIa).

As a part of investigations on the tautomerism of indene and indene derivatives, ${ }^{1}$ a good preparative method for the synthesis of $1_{-}$, and especially, 1,3-disubstituted, indenes was required. The fact that the methylene moiety of indene is slightly acidic $\left(\mathrm{p} K_{\mathrm{a}}=21\right)$ has enabled several workers to prepare metal compounds of indene. ${ }^{2-5}$ These compounds could then be used to prepare alkylated indenes. ${ }^{5,6}$ However, in most cases in the earlier literature, there is some doubt as to whether a 1-or a 3-substituted indene has been formed. The reaction conditions have sometimes been too vigorous and led to a mixture of products. High temperature or prolonged heating leads to the more stable 3-substituted isomer. However, high temperature is often needed with sluggish reacting reagents such as sodium, sodamide, and alkali-hydroxides in the first step and secondary and tertiary halides in the second step. 1-Substituted indenes have also been prepared in an essentially isomeric pure state from indenylmagnesium bromide and an alkyl halide." This reaction is, however, restricted to the more reactive halides such as benzyl chloride and gives rather poor yields.

With ethyllithium in ether in an inert atmosphere, indene forms a compound, which can be isolated as yellowish crystals. Schlenk and Bergmann ${ }^{4}$ used this compound to prepare benzhydrylindene (m.p. $158^{\circ} \mathrm{C}$ ) by reacting it with benzhydryl chloride. When this indenederivative was treated with methanolic potassium hydroxide, a compound with a melting point of $108-109^{\circ} \mathrm{C}$ was found. They concluded that the compound first isolated was the 1substituted isomer, which was rearranged to 3benzhydrylindene in the base-catalyzed reaction. This finding has been confirmed in the present paper by means of NMR data. The metalation and alkylation procedures used by these authors were thus mild enough to permit isolation of the least stable isomer.

In these laboratories preparations of pure 1substituted and 1,3-disubstituted derivatives have been achieved. Thus, 1,3-dideuterio-indene has been prepared by heating 1,1,3-trideuterioindene with a sodium dispersion, followed by quenching the reaction mixture with $\mathrm{H}_{2} \mathrm{O} .^{9}$ Ahlberg et al. prepared 1- $\alpha$-hydroxyisopropylindene by reacting indenyllithium with acetone. ${ }^{6}$ Isomeric pure 1-deuterio-2-ethylindene has also been prepared and these results will be published elsewhere. ${ }^{10}$

A few years ago, Meth-Cohn and Gronowitz prepared indene-1-carboxylic acid from carbon dioxide and indenyllithium. ${ }^{11}$ Quite recently Cedheim and Eberson have reported the preparation of several 1-alkylindenes from indenyl-

Acta Chem. Scand. B 28 (1974) No. 3 
lithium. ${ }^{12}$ As quoted in their paper indenyllithium had earlier been used for the preparation of 1-benzyl-, 1-benzhydryl-, and 1-triphenylmethylindene. This paper describes the use of indenyllithium compounds for the preparation of both 1- and 1,3-alkylsubstituted indenes. Contrary to the findings of others, ${ }^{12}$ no need was found for using the method of reversed addition of reagents.

\section{RESULTS AND DISCUSSION}

The metalation of indene was performed by treating indene with a $50 \%$ excess of butyllithium in pentane or ether. The reaction was exothermic and was controlled by external cooling. The metalation was complete within 15 min, since quenching with $\mathrm{D}_{2} \mathrm{O}$, followed by rapid acidification, showed more than $98 \%$ monodeuteration in the indene isolated, as judged from the NMR-spectrum. In one experiment the ether was removed after adding a two-fold excess of butyllithium, xylene was added and the reaction mixture heated for $12 \mathrm{~h}$. After quenching with $\mathrm{D}_{2} \mathrm{O}$ and conventional work-up, the NMR-spectrum of the product was examined. The spectrum showed only monodeuteration (i.e. one equivalent of butyllithium had reacted) which is opposite to the results obtained by others under similar conditions. ${ }^{13}$

The alkylation was performed by adding an excess of alkyl halide to a cooled ethereal

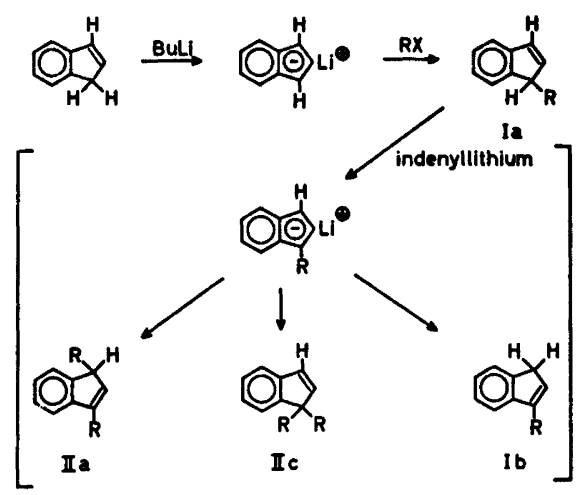

Scheme 1.

solution of indenyllithium in a nitrogen atmosphere. After standing for the appropriate time and temperature (see Table 1) with stirring, the reaction mixture was poured into icecooled, $2 \mathrm{M}$ hydrochloric acid. After work-up and preparative GLC, the product was analyzed with NMR and analytical GLC. This showed that the reaction mixture consisted of the starting material and isomeric pure 1-alkylindene in different proportions, depending on the alkyl halide used. A complication in these syntheses is that excessively high temperature and/or prolonged reaction time lead to 3 . alkylindenes or dialkylation (1,3-dialkylation and 1,1-dialkylation) presumably according to scheme 1. Thus when indenyllithium was

Table 1. Alkylation of indenyllithium in ether with various alkylhalides ( $c f$. Scheme 1). Retention times are given for the analytical column described in the experimental part. Retention time for indene: $9.0 \mathrm{~min}$.

\begin{tabular}{llllll}
\hline $\begin{array}{l}\text { Alkylating } \\
\text { agent }\end{array}$ & $\begin{array}{l}\text { Reaction } \\
\text { temp. }\end{array}$ & $\begin{array}{l}\text { Reaction } \\
\text { time } \mathrm{C} .\end{array}$ & $\begin{array}{l}\text { Yield of } \\
\text { Ia }(\%)\end{array}$ & $\begin{array}{l}\text { Retention } \\
\text { time of } \\
\text { Ia (min) }\end{array}$ & $\begin{array}{l}\text { Retention time } \\
\text { of rearranged } \\
\text { prod. Ib (min) }\end{array}$ \\
\hline $\mathrm{CH}_{3} \mathrm{I}$ & -20 & 18 & 93 & 10.4 & 15.4 \\
$\mathrm{C}_{2} \mathrm{H}_{5} \mathrm{Br}$ & +5 & 18 & 74 & 16.2 & 20.5 \\
$\mathrm{i}-\mathrm{C}_{3} \mathrm{H}, \mathrm{Br}$ & +25 & 11 & 69 & 20.1 & 27.9 \\
$t \cdot \mathrm{C}_{4} \mathrm{H}_{9} \mathrm{Br}$ & +25 & 18 & 35 & 27.6 & 36.4 \\
$t-\mathrm{C}_{4} \mathrm{H}_{9} \mathrm{Br}$ & $+25^{a}$ & 12 & 48 & 27.6 & 36.4 \\
$t-\mathrm{C}_{4} \mathrm{H}_{8} \mathrm{Br}$ & +35 & 8 & 45 & 27.6 & 36.4 \\
$\mathrm{C}_{6} \mathrm{H}_{6} \mathrm{CH} \mathrm{H}_{2} \mathrm{Cl}$ & +25 & 4 & 84 & - & - \\
$\left(\mathrm{C}_{6} \mathrm{H}_{5}\right)_{2} \mathrm{CHCl}$ & +25 & 4 & 73 & - & - \\
$\left(\mathrm{C}_{6} \mathrm{H}_{5}\right)_{3} \mathrm{CCl}$ & +25 & 2 & 81 & - & - \\
\hline
\end{tabular}

a Equimolar amount of DMSO added. 
methylated at room temperature and the solution left for $18 \mathrm{~h}$, the product consisted of $78 \%$ 1-methylindene, $12 \% 3$-methylindene, and $10 \%$ dimethylated indenes. Bosch and Brown ${ }^{5}$ reported similar results except that they found a larger portion of 3-methylindene. However, if the temperature is kept below $-20^{\circ} \mathrm{C}$ in the alkylation step, $93 \% 1$-methylindene, about $0.5 \% 3$-methylindene, and $1.5 \%$ dimethylated products are obtained. Even if a low reaction temperature is necessary, it was found that heating can increase the yield of the 1-substituted indene. Thus heating a mixture of indenyllithium and $t$-butyl bromide increased the yield of 1-t-butylindene from 35 to $45 \%$ without isomerization.

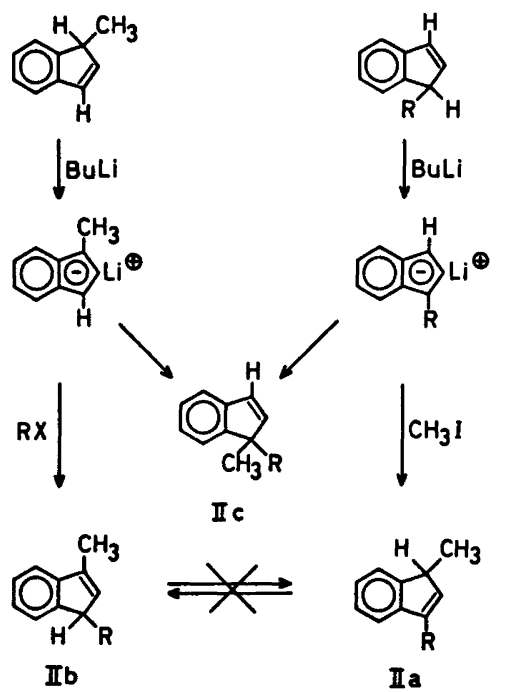

Scheme 2.

Alkylation of alkyl-indenyllithium compounds is supposed to occur in both the 1and the 3-position and result in the formation of 1,1- and 1,3-dialkylindenes (Scheme 2). However, the distribution and yields of these two species vary considerably depending on the substituent in the indene nucleus and the type of alkyl halide used. Methylation of methylindenyllithium thus gave about $10 \% 1,1$ disubstitution while the same reaction with $t$-butylindenyllithium gave no 1,1-disubstituted product. Ethyl- and isopropylindenyllithium gave yields between these two extremes, while 1-benzylindenyllithium gave about the same amount of the 1,1-disubstituted products as methylindenyllithium (Table 2). However, when methylindenyllithium was alkylated with various alkyl halides (Table 3), the amount of 1,1disubstitution increased with the bulkiness of the alkylating agent. Thus, $t$-butylbromide gave $55 \%$ 1,1-disubstitution (calculated on the total amount of the disubstituted product), while methyl iodide gave only $10 \%$. When dimethoxyethane was used as solvent, the relative amount of 1,1-disubstitution was diminished to about $45 \%$. Benzyl chloride gave about the same amount of 1,1-disubstitution as $t$-butyl bromide. The varying amounts of 1,1-disubstitution is, of course, a disadvantage but, since separation is fairly easy with preparative GLC, the method can be of synthetic value since the previous routes to 1,3-dialkylindenes have been long and tedious. It should also be mentioned that the synthesis of IIa, the least stable isomer, gives the desired product in high yield, only slightly contaminated with 1,1-dialkylated product. No tautomeric mixture (IIa + IIb) is formed in either case (Tables 2 and 3).

For comparison it may be mentioned that quenching of methylindenyllithium with water under controlled conditions, i.e. so that no rearrangement can occur, gave exclusively 3 methylindene.

The different trends observed in the proportion of 1,1-dialkylated product (IIc in Scheme 2) obtained in the methylation procedure (Table 2) compared to the alkylation procedure (Table 3) are difficult to account for. In the methylation experiments, the benzyl substituent gives a result which resembles that found for the methyl substituent rather than for the higher alkyls (Table 2). Thus, a simple steric effect cannot account for the results. In the alkylation of methylindenyllithium, benzyl chloride shows, however, more similarity to the higher alkyl halides than to methyl iodide (Table 3). The entire trend in these experiments is thus opposite to that expected if simple steric hindrance between methyl and alkyl is considered. A more detailed study, especially regarding the structure of the indenyllithium compounds, is probably needed before any safe explanation can be given for the above-mentioned facts. This is beyond the scope of the present paper although a few further comments seem appropriate.

Acta Chem. Scand. B 28 (1974) No. 3 
Table 2. Methylation of various alkylindenyllithium compounds in ether with methyl iodide(cf. Scheme 2). Reaction time $18 \mathrm{~h}$. Reaction temperature $25^{\circ} \mathrm{C}$. Retention times were obtained under the conditions given in the experimental part.

\begin{tabular}{lllll}
\hline $\begin{array}{l}\text { Indenyllithium } \\
\text { compound }\end{array}$ & $\begin{array}{l}\text { Yield of } \\
\text { IIa (\%) }\end{array}$ & $\begin{array}{l}\text { Retention time of } \\
\text { IIa (min) }\end{array}$ & $\begin{array}{l}\text { Yield of } \\
\text { IIc (\%) }\end{array}$ & $\begin{array}{l}\text { Retention time of } \\
\text { IIc (min) }\end{array}$ \\
\hline Methyl- & 82 & 17.5 & 8 & 9.5 \\
Ethyl- & 76 & 23.5 & 5 & 14.2 \\
Isopropyl- & 78 & 27.5 & 2 & 20.5 \\
$t$-Butyl- & 72 & 34.1 & 0 & 30.5 \\
Benzyl- & 70 & $-a$ & 12 & - \\
\hline
\end{tabular}

${ }^{a}$ Not isolated. Identification and determination of yield via NMR-spectroscopy.

Table 3. Alkylation of methylindenyllithium in ether with various alkyl halides (cf. Scheme 2). Reaction time $18 \mathrm{~h}$. Reaction temperature $25^{\circ} \mathrm{C}$. Retention times were obtained under the conditions given in the experimental part.

\begin{tabular}{lllll}
\hline $\begin{array}{l}\text { Alkylating } \\
\text { agent }\end{array}$ & $\begin{array}{l}\text { Yield of } \\
\text { IIb }(\%)\end{array}$ & $\begin{array}{l}\text { Retention time of } \\
\text { IIb (min) }\end{array}$ & $\begin{array}{l}\text { Yield of } \\
\text { IIc (\%) }\end{array}$ & $\begin{array}{l}\text { Retention time of } \\
\text { IIc (min) }\end{array}$ \\
\hline $\mathrm{CH}_{3} \mathrm{I}$ & 82 & 17.5 & 8 & 9.5 \\
$\mathrm{C}_{2} \mathrm{H}_{5} \mathrm{Br}$ & 65 & 22.5 & 16 & 14.2 \\
$\mathrm{i}-\mathrm{C}_{3} \mathrm{H}_{7} \mathrm{Br}$ & 35 & 29.0 & 23 & 20.5 \\
$t-\mathrm{C}_{4} \mathrm{H}_{8} \mathrm{Br}$ & 14 & 40.0 & 17 & 30.5 \\
$t-\mathrm{C}_{4} \mathrm{H}_{8} \mathrm{Br}^{a}$ & 15 & 40.0 & 21 & 30.5 \\
$\mathrm{C}_{6} \mathrm{H}_{5} \mathrm{CH}_{2} \mathrm{Cl}^{b}$ & 35 & - & 40 & - \\
$\mathrm{C}_{6} \mathrm{H}_{5} \mathrm{CH}_{2} \mathrm{Cl}^{b}, c$ & 43 & - & 32 & - \\
\hline
\end{tabular}

${ }^{a}$ Equimolar amount of DMSO added. ${ }^{b}$ Not isolated. Composition and yields determined with NMR spectroscopy. ${ }^{c}$ Solvent: Dimethoxyethane.

The fact that tautomeric mixtures $(\mathrm{IIa}+\mathrm{IIb})$ are not formed in any of the alkylation procedures (Scheme 2, Tables 2 and 3) and that formation of 3-alkylindenes ( $\mathrm{Ib}$, Scheme 1 and Table 1) can be avoided, indicates that the indenyllithium compounds must be present in the form of covalent species or contact ion pairs. Solvent separated ion pairs or indenyl anions would bring about a fast isomerization of the alkylindenes formed. ${ }^{1}$

The bonding in delocalized organolithiums varies considerably depending on the stability of the carbanion and the nature of the solvent. ${ }^{14}$ Fluorenyllithiums in dioxane occur in the form of contact ion pairs exclusively and in tetrahydrofurane as a mixture of contact and solvent-separated ion pairs. ${ }^{15}$ In cyclohexylamine-diethylamine indenyllithium exists as $65 \%$ solvent-separated ion pairs and $35 \%$ contact ion pairs at room temperature. ${ }^{16} \mathrm{Com}$ - pared to the fluorenyl anion, the indenyl anion has a more concentrated negative charge and forms a relatively more stable contact ion pair. ${ }^{16}$ These data suggest that indenyllithium in ether should exist mainly as contact ion pairs ( $c f$. Ref. 17). Alkyl substituted fluorenyllithiums show a greater proportion of solvent separated ion pairs as compared to the fluorenyllithium itself. ${ }^{14,16}$ Whether this is true for the indenyl. lithiums cannot be decided since in this allylic system there may be an equilibrium between two contact ion pairs, with the lithium ion situated above either the 1- or the 3-position. Indenyllithium in tetrahydrofuran has an NMR. spectrum in which $\mathrm{H}_{1}$ and $\mathrm{H}_{3}$ are magnetically equivalent. This has been explained as the result of a rapid equilibrium between two covalent structures. ${ }^{18}$ The spectrum can, how. ever, also be accounted for as a result of a contact ion pair or an equilibrium between two 
such ion pairs in view of the facts mentioned above and of other studies of allyllithium compounds. ${ }^{14}$

The situation in the relatively concentrated solutions used in the preparative procedures is certainly rather complex, since it is known that allyllithium is highly aggregrated in concentrated ether solution. ${ }^{14}$ However, if we may use the simple hypothesis that contact ion pairs and high polarity of the solvent are favourable for the desired outcome of the alkylation reactions, the use of a larger cation than lithium should be preferred, ${ }^{15}$ although the use of such cations will present larger preparative problems.

\section{EXPERIMENTAL}

General. Preparative GLC was performed on a Varian Aerograph 90-P, equipped with a $4 \mathrm{~m} \times 3 / 8^{\prime \prime}$ column filled with $15 \%$ Apiezon $\mathrm{L}$ on Chromosorb 80/100 mesh with a gas-flow of about $100 \mathrm{ml} / \mathrm{min}$. The column temperature was held constant at a temperature between 120 and $150^{\circ} \mathrm{C}$ depending on the indene being examined. Tests of indene purity were made on a Perkin-Elmer 900 gas-chromatograph with a flame ionization detector on a $8 \mathrm{~m} \times 1 / 8^{\prime \prime}$ column filled with $8 \%$ Apiezon L on Varaport 30, 100/120 mesh. The column temperature was $150^{\circ} \mathrm{C}$ and the initial pressure $1 \mathrm{~kg} / \mathrm{cm}^{2}$. The NMR-spectra were run on a Varian A 60 D NMR-spectrometer. The samples were about $20 \%$ in $\mathrm{CCl}_{4}$ and run at $35^{\circ} \mathrm{C}$ with tetramethylsilane as an internal standard. The aralkylindenes were run in benzene- $d_{6}$.

Alkylation procedure. Butyllithium ${ }^{19} \quad(15$ $\mathrm{mmol}$ ) in $10 \mathrm{ml}$ of pentane was added to a cooled solution of indene (or 1-alkylindene) $(10 \mathrm{mmol})$ in $50 \mathrm{ml}$ of dry ether in an atmosphere of dry nitrogen, purified over a solution of triphenylmethanide anion in pyridine. ${ }^{20}$ The resulting solution was stirred at room temperature for about $30 \mathrm{~min}$. The appropriate alkyl halide, bromide or iodide, $(20 \mathrm{mmol})$ in $10 \mathrm{ml}$ of ether was added with cooling to the reaction mixture. Samples were withdrawn and analyzed on the gas chromatograph. After standing at the appropriate temperature for the time scheduled in Tables 1-3, the brown-coloured solution was poured on to $100 \mathrm{ml}$ of ice-cooled $2 \mathrm{M}$ hydrochloric acid. The ether phase was separated, the aqueous phase extracted with ether and the combined ether extracts washed with aqueous $\mathrm{NaCl}$ sat. and dried over $\mathrm{MgSO}_{4}$. The ether extracts were decolourized with charcoal and the ether evaporated. The residue was purified with preparative GLC in $250 \mu$ portions. In most cases sufficient purity, $\leq 1 \%$ impurities, was

Table 4. NMR-data for benzhydrylindene and triphenylmethylindene in benzene- $d_{6}$ at $35^{\circ} \mathrm{C}$. Concentration: $0.3 \mathrm{M}$.

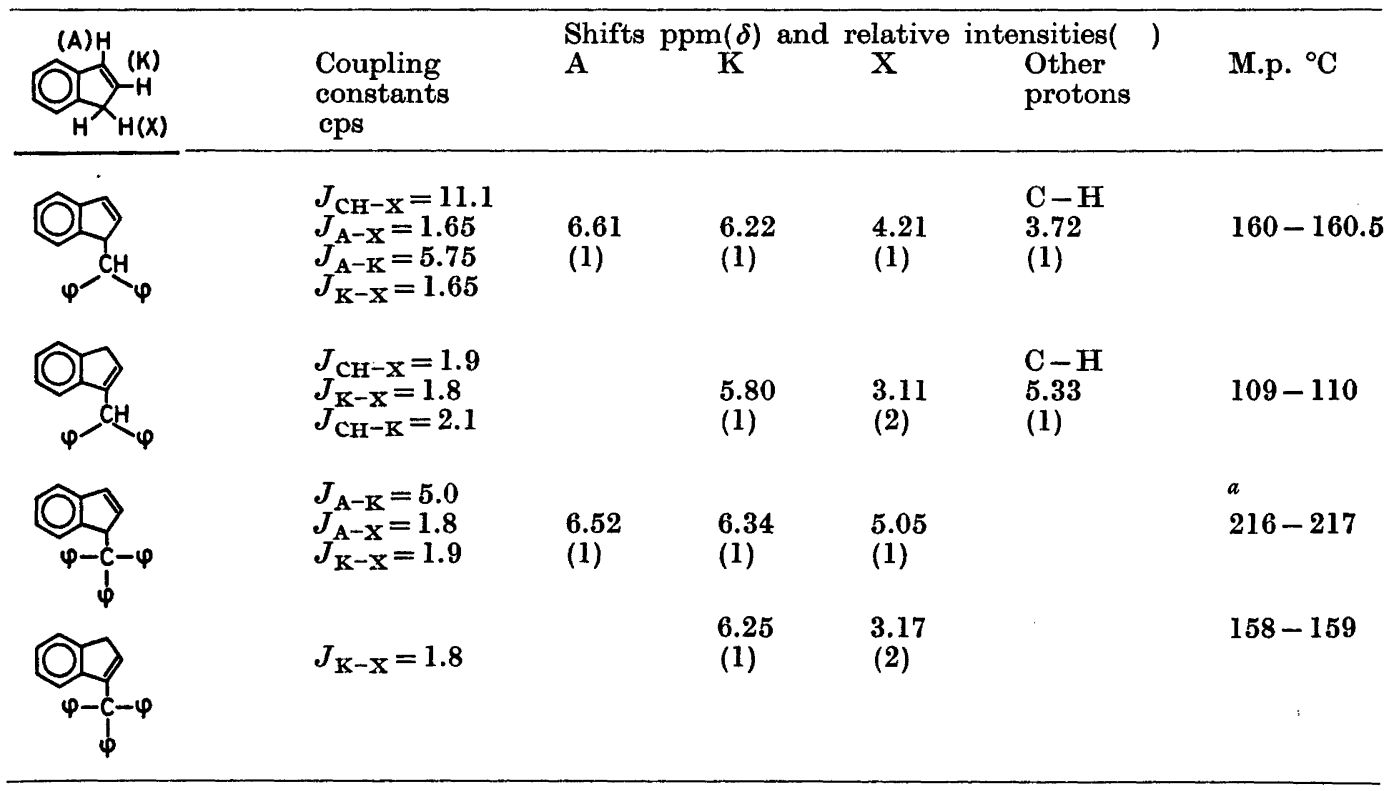

a Anal. Found: $\mathrm{C} 93.71 ; \mathrm{H}$ 6.12. Calc. for $\mathrm{C}_{28} \mathrm{H}_{22}$ : $\mathrm{C}$ 93.85; $\mathrm{H}$ 6.15.

Acta Chem. Scand. B 28 (1974), No. 3 
obtained with a spinning band column, if the reactions were run in larger batches.

1-Benzylindene was prepared from $100 \mathrm{mmol}$ of indenyllithium and $200 \mathrm{mmol}$ of benzyl chloride and the product subjected to fractional destillation. Since none of the aralkylindenes can be purified via GLC, 1-benzhydrylindene and 1-triphenylmethylindene were recrystallized from isopropanol. 3-Aralkylindene was isolated from equilibrium mixtures after isomerization experiments, the results of which will be published separately. ${ }^{21}$ The equilibrium constant was larger than 50 and the 3-aralkylindenes were purified by destillation (3-benzylindene) or recrystallization from isopropanol. Melting points and NMR-data are shown in Table 4. NMR-data for 1,1-dialkylindenes are given in Table 5 .

Table 5. NMR-data for 1,1-dialkylindenes in carbontetrachloride at $35^{\circ} \mathrm{C}$. Concentration: 1 M. Shifts $(\delta)$ relative TMS. $J_{\mathrm{A}-\mathrm{K}}=5.50 \mathrm{cps}$.

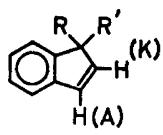

\begin{tabular}{llll}
$\mathbf{R}$ & $\mathbf{R}^{\prime}$ & $\mathbf{K}$ & $\mathbf{A}$ \\
\hline
\end{tabular}

$\begin{array}{lrll}\mathrm{R}=\mathrm{R}^{\prime}=\mathrm{CH}_{3}- & & \\ 1.32 & 1.32 & 6.21 & 6.49 \\ 3 \mathrm{H} & 3 \mathrm{H} & 1 \mathrm{H} & 1 \mathrm{H}\end{array}$

$\begin{array}{lccc}\mathrm{R}=\mathrm{CH}_{3}-, & \mathrm{R}^{\prime}=\mathrm{CH}_{3} \mathrm{CH}_{2}- & & \\ 1.29 & 0.61 & 6.11 & 6.55 \\ 3 \mathrm{H} & 3 \mathrm{H} & 1 \mathrm{H} & 1 \mathrm{H} \\ & 1.78 & & \end{array}$

\begin{tabular}{lccc}
$\mathrm{R}=\mathrm{CH}_{3}-, \mathrm{R}^{\prime}=\left(\mathrm{CH}_{3}\right)_{2} \mathrm{CH}-$ & \\
1.24 & $1.02,0.60$ & 6.18 & 6.59 \\
$3 \mathrm{H}$ & $6 \mathrm{H}$ & $1 \mathrm{H}$ & $1 \mathrm{H}$ \\
& 2.42 & & \\
& $1 \mathrm{H}$ & & \\
\multicolumn{5}{c}{$\mathrm{CH}_{3}-, \mathrm{R}^{\prime}=\left(\mathrm{CH}_{3}\right)_{3} \mathrm{C}-$} & & \\
1.27 & 0.95 & 6.25 & 6.52 \\
$3 \mathrm{H}$ & $9 \mathrm{H}$ & $1 \mathrm{H}$ & $1 \mathrm{H}$ \\
\hline
\end{tabular}

Acknowledgements. The author thanks Professor G. Bergson for helpful advice and for all facilities placed at his disposal. A grant from The Swedish Natural Science Research Council is gratefully acknowledged.

\section{REFERENCES}

1. Bergson, G. and Ohlsson, L. Acta Chem. Scand. 23 (1969) 2175, and earlier paper in this series.

2. Blum-Bergmann, O. Justus Liebigs Ann. Chem. 484 (1930) 26.

3. Courtot, C. Ann. Chim. (Paris) [9] 4 (1915) 76.

4. Schlenk, A. and Bergmann, E. Justus Liebigs Ann. Chem. 463 (1920) 227.

5. Bosch, A. and Brown, R. K. Can. J. Chem. 42 (1964) 1728.

6. Ahlberg, P. Chem. Scr. 3 (1973) 183.

7. Courtot, C. Ann. Chim. (Paris) 5 (1916) 75.

8. Weidler, A. M. Acta Chem. Scand. 17 (1963) 2724.

9. Bergson, G. Acta Chem. Scand. 18 (1964) 2003.

10. Meurling, L. Acta Chem. Scand. To be published.

11. Meth-Cohn, O. and Gronowitz, S. Chem. Commun. (1966) 81.

12. Cedheim, L. and Eberson, L. Synthesis (1973) 159.

13. Sommer, L. H. and Marans, N. S. J. Amer. Chem. Soc. 73 (1951) 5135.

14. McKeever, L. D. In Swarc, M., Ed., Ions and Ionpairs in Organic Reactions, Wiley. Interscience, New York 1973, Vol. I, p. 273.

15. Hogen-Esch, T. E. and Smid, H. J. Amer. Chem. Soc. 88 (1966) 307.

16. Streitwieser, Jr., A., Chang, C. J., Hollyhead, W. B. and Murdoch, J. R. J. Amer. Chem. Soc. 94 (1972) 5288.

17. Wagner, B. O. and Ebel, H. F. Tetrahedron $26 \quad(1970) \quad 5155$.

18. Kitching, W. and Hegarty, B. J. Organo. metal. Chem. 16 (1969) P39.

19. Gilman, H., Moore, F. W. and Baine, O. J. Amer. Chem. Soc. 63 (1941) 2479.

20. Lansbury, P. T. J. Amer. Chem. Soc. 83 (1961) 429.

21. Meurling, L. Acta Chem. Scand. To be published.

Received November 15, 1973. 